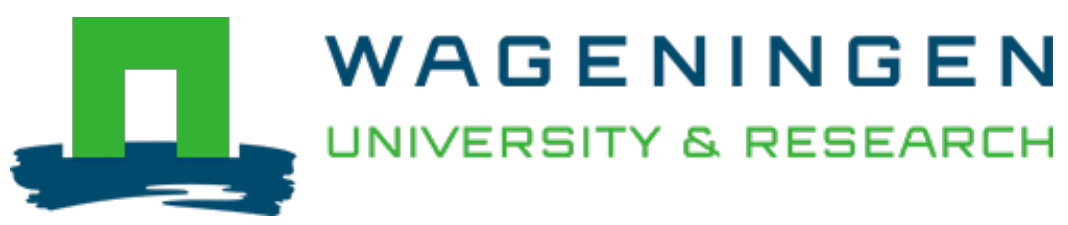

\title{
Simple screening procedure for microorganisms to degrade amygdalin.
}

Biotechnology techniques

Brimer, L.; Tunçel, G.; Nout, M.J.R.

https://doi.org/10.1007/bf00151870

This publication is made publicly available in the institutional repository of Wageningen University and Research, under the terms of article $25 \mathrm{fa}$ of the Dutch Copyright Act, also known as the Amendment Taverne. This has been done with explicit consent by the author.

Article $25 \mathrm{fa}$ states that the author of a short scientific work funded either wholly or partially by Dutch public funds is entitled to make that work publicly available for no consideration following a reasonable period of time after the work was first published, provided that clear reference is made to the source of the first publication of the work.

This publication is distributed under The Association of Universities in the Netherlands (VSNU) 'Article $25 \mathrm{fa}$ implementation' project. In this project research outputs of researchers employed by Dutch Universities that comply with the legal requirements of Article $25 \mathrm{fa}$ of the Dutch Copyright Act are distributed online and free of cost or other barriers in institutional repositories. Research outputs are distributed six months after their first online publication in the original published version and with proper attribution to the source of the original publication.

You are permitted to download and use the publication for personal purposes. All rights remain with the author(s) and / or copyright owner(s) of this work. Any use of the publication or parts of it other than authorised under article $25 \mathrm{fa}$ of the Dutch Copyright act is prohibited. Wageningen University \& Research and the author(s) of this publication shall not be held responsible or liable for any damages resulting from your (re)use of this publication.

For questions regarding the public availability of this publication please contact openscience.library@,wur.nl 

AMYGDALIN

L. Brimerl, G. Tunçel ${ }^{2}$, and M.J.R. Nout ${ }^{3 *}$

${ }^{1}$ Department of Pharmacology and Pathobiology, The Royal Veterinary and Agricultural University, 13 Bülowsvej, DK-1870 Frederiksberg $c$, Copenhagen, Denmark; Faculty of Engineering, Ege University, 35100 Bornova-Izmir, Turkey; ${ }^{3}$ Department of Food Science, Agricultural University, Bomenweg 2, 6703 HD Wageningen, The Netherlands.

\section{Summary:}

Amygdalin is a cyanogenic glycoside occurring among others in almonds and bitter apricot seeds. Utilization of seeds for human or animal nutrition requires adequate detoxification. The present method for screening microbial cultures for their ability to degrade amygdalin is a convenient micro-titre version based on the picrate reaction principle.

\section{Introduction:}

Bitter apricot seeds are by-products of the apricot processing industry. The seeds have a high protein content and could be used as a food or feed ingredient. However, they contain approximately $50 \mathrm{nmol}$ of the potentially toxic cyanogenic glycosides amygdalin and prunasin per $\mathrm{mg}$. We reported earlier (Tunçel et al. 1990) on prospects for their detoxification by biotechnological means, i.e. by using the endogenous enzymes combined with microbial fermentation. The tempe fermentation process using the fungus Rhizopus oligosporus as inoculant enabled about $70 \%$ of total cyanide potential to be removed. As we considered this inadequate from toxicological point of view, we developed a simple method based on the picrate test (Guignard 1906), as used by Brimer and Moelgaard (1986), to screen microbial strains for their ability to degrade amygdalin by hydrolysis. This paper describes the method and gives selected preliminary data on amygdalin degradation by lactic acid bacteria, yeasts and filamentous rungi.

Experimental methods:

Materials: D-Amygdalin (Sigma St.Louis USA, A6005) was used for standard as a standard as a $1 \mathrm{~mm}$ solution in distilled 
water. Pectinase (EC 3.2.1.15) from Rhizopus sp. (Sigma St.Louis USA, P2401) was used as a source of hydrolytic enzymes (Brimer and Rosling 1993), for positive controls, as a $0.2 \% \mathrm{w} / \mathrm{v}$ solution in distilied water. Picrate reagent sheets were prepared according to Brimer et al. (1983) as follows: pre-coated ion-exchange sheets (Polygram ionex 25-SB-AC, Machery-Nagel, Düren, Germany) were cut to size (dimensions of microtiter plate), and were impregnated by immersion (plastic side up) in saturated picric acid aquous solution, followed by blotting on absorbent paper, drying with hot air (hairdryer), immersion in $1 \mathrm{M} \mathrm{Na}_{2} \mathrm{CO}_{3}$ solution (plastic side up), and drying with hairdryer. Microbial cultures from to be tested were suspended (10 $\mathrm{mg}$ wet weight $/ \mathrm{mL}$ ) in sterile saline $(8.5 \mathrm{~g}$ $\mathrm{NaCl} / \mathrm{L}$ ) .

Procedure: In a microtiter plate, the following wells are prepared: (a) positive control (4 wells/plate): $20 \mu \mathrm{L}$ amygdalin $+20 \mu \mathrm{L}$ pectinase $+180 \mu \mathrm{L}$ saline; (b) negative control (4 wells/plate): $20 \mu \mathrm{L}$ amygdalin $+200 \mu \mathrm{L}$ saline; (c) test ( 8 cultures in duplicate/plate): $20 \mu \mathrm{L}$ amygdalin $+200 \mu \mathrm{L}$ microbial suspension. Place a picrate reagent sheet (plastic side up) on top of the microtiter plate, weigh it down gently with a flat object of approx. $100 \mathrm{~g}$, and incubate at $25^{\circ} \mathrm{C}$ overnight.

Assessment: The red-brown spots on yellow background, typical of positive reactions, were assessed either qualitatively by visually estimating their colour intensity as $0,1,2,3$; or semi-quantitatively by measuring the extinction of reflected light at $550 \mathrm{~nm}$ using a microtitre plate reader. The extent of amygdalin degradation is calculated as a fraction $\%$ of the extinction produced by the positive control.

Results and Discussion:

Table 1 presents the results of the qualitative assessment of a number of lactic acid bacteria, yeasts and filamentous fungi. In Table 2 the semi-quantitative assessment of amygdalin degradation by selected food-grade micro-organisms is presented.

From Table 1 it can be seen that approximately $45 \%$ of the tested lactic acid bacteria (mainly L.plantarum strains) have a weak to medium ability to degrade amygdalin, the rest being negative. On the other hand, about $71 \%$ of the tested yeasts and $96 \%$ of the filamentous fungi have a medium to strong ability to degrade amygdalin.

The data of Table 2 indicate firstly that not all strains having a score "3" in Table 1 give a high percentage of degradation. Besides variations concerning cell numbers etc., this is caused mainly by the difficulty of making visual distinctions between -especially strong-colour intensities. All showing a score of 2 or 3 do, however, as anticipated show 
degradation in the second experiment. Table 2 also indicates that some of the cultures of yeasts and filamentous fungi are much more powerful amygdalin degraders compared with lactic acid bacteria.

Table 1. Ability of lactic acid bacteria, yeasts and filamentous fungi to degrade amygdalin.

Lactic acid bacteria:

Enterococcus faecalis

Enterococcus faecalis

Lactobacillus acidophilus

Lactobacillus acidophilus

Lactobacillus acidophilus 1

Lactobacillus acidophilus 1

Lactobacillus acidophilus 1

Lactobacillus acidophilus

Lactobacillus acidophilus

Lactobacillus acidophilus

Lactobacillus brevis

Lactobacillus casei

Lactobacillus casei var. casei

Lactobacillus casei var. tolerans

Lactobacillus coprophilus

Lactobacillus delbrückii

Lactobacillus fermentum

Lactobacillus plantarum

Lactobacillus plantarum

Lactobacillus plantarum

Lactobacillus plantarum

Lactobacillus plantarum

Lactobacillus plantarum

Lactobacillus plantarum

Lactobacillus plantarum

Lactococcus lactis

Pediococcus acidilactici

pediococcus acidilactici

pediococcus acidilactici

\section{Yeasts:}

Candida guilliermondii

Candida intermedia

Candida Iusitaniae

Candida maltosa komagata

Hanseniaspora valbyensis

Hansenula anomala

Hansenula fabianii

Kluyveromyces marxianus

Pichia anomala

Pichia guilliermondii

Rhodotorula mucilaginosa

Rhodotorula rubra

\begin{tabular}{|c|c|}
\hline Code ${ }^{*}:$ & Score ${ }^{* *}:$ \\
\hline 9790 & 0 \\
\hline 8043 & 0 \\
\hline $\mathrm{SBO} 2$ & 0 \\
\hline SB003 & 0 \\
\hline $\mathrm{SBO04}$ & 0 \\
\hline SB006 & 0 \\
\hline SB17 & 1 \\
\hline SB023 & 1 \\
\hline SB026 & 1 \\
\hline $\mathrm{SBO} 44$ & 0 \\
\hline SB001 & 1 \\
\hline- & 0 \\
\hline - & 0 \\
\hline - & 0 \\
\hline SB019 & 0 \\
\hline SBO 24 & 1 \\
\hline 20049 & 0 \\
\hline SB035 & 0 \\
\hline SGI & 2 \\
\hline 845 & 2 \\
\hline P743 & 1 \\
\hline 111 & 2 \\
\hline MS 7 & 1 \\
\hline C31 & 1 \\
\hline 832 & 2 \\
\hline PC1 & 0 \\
\hline M301 & 0 \\
\hline- & 2 \\
\hline M324 & 0 \\
\hline 132 & 1 \\
\hline 121 & 2 \\
\hline 123 & 3 \\
\hline 124 & 2 \\
\hline 263 & 3 \\
\hline 261 & 1 \\
\hline 262 & 1 \\
\hline 321 & 2 \\
\hline 530 & 2 \\
\hline 502 & 0 \\
\hline 586 & 0 \\
\hline 596 & 0 \\
\hline
\end{tabular}


Yeasts (continued)

Saccharomyces cerevisiae Saccharomyces cerevisiae Saccharomycopsis fibuligera Saccharomycopsis fibuligera Schizosaccharomyces pombe Schizosaccharomyces pombe Trichosporon beigelii Yarrowia lipolytica zygosaccharomyces bailii

Filamentous fungi:

Aspergilius oryzae Aspergillus oryzae var. brunneus Aspergillus oryzae var. effusus Aspergillus tamarii Botrytis cinerea Geotrichum candidum Geotrichum candidum Mucor hiemalis Mucor circinelloides Mucor circinelloides Mucor circinelloides Mucor indicus

Neosartorya fischeri Neurospora sp.

Penicillium brevicompactum

Penicillium camemberti

Penicillium nalgiovense

Pleurotus sajor-caju

Rhizopus microsporus

Rhizopus oligosporus NRRL5905

Rhizopus oligosporus

Rhizopus oryzae

Rhizopus oryzae

Rhizopus oryzae

syncephalastrum racemosum

\begin{tabular}{|c|c|}
\hline Code & Score \\
\hline 672 & 0 \\
\hline 671 & 0 \\
\hline 677 & 3 \\
\hline 676 & 2 \\
\hline 685 & 1 \\
\hline 686 & 0 \\
\hline 692 & 2 \\
\hline 771 & 1 \\
\hline 781 & 1 \\
\hline
\end{tabular}

$007 \quad 2$

$008 \quad 2$

$009 \quad 1$

$015 \quad 2$

$101 \quad 1$

$241 \quad 1$

$242 \quad 0$

$363 \quad 2$

M40 3

$361 \quad 3$

3623

3652

$431 \quad 2$

- 3

$514 \quad 1$

$504 \quad 1$

$520 \quad 3$

$503 \quad 2$

$573 \quad 2$

$575 \quad 2$

$578 \quad 2$

$580 \quad 3$

$581 \quad 2$

$582 \quad 1$

6813

${ }^{*}=$ from the collection of the Department of Food Science, Agricultural University, Wageningen;

${ }^{* *}=$ score according to colour intensity of picrate test (qualitative). 
Table 2. Semi-quantitative assessment of ability to degrade amygdalin by selected food-grade micro-organisms.

culture

Bacteria:

Lactobacilius plantarum Lactobacillus plantarum Lactobacillus plantarum Lactobacilius plantarum Pediococcus acidilactici Yeasts:

Candida lusitaniae

Hanseniaspora valbyensis Saccharomycopsis fibuligera Filamentous fungi: Mucor circinelloides Mucor circinelloides Mucor circinelloides Neurospora sp. Penicillium nalgiovense Rhizopus oligosporus Rhizopus oryzae Syncephalastrum racemosum
Code*

832

$\mathrm{SG} 1$

845

111

$-$

123

263

677

361

362

M40

$-$

520

575

580

681
Score ${ }^{* *}$

\%degradation

$*, * *$ : as in Table 1 .

Acknowledgement:

The financial support by NATO Collaborative Research Grant 920009 is gratefully acknowledged.

\section{References:}

Brimer, L., Brøgger Christensen, S., Moelgaard, P. and Nartey, F. (1983). J.Agric.Food Chem. 31, 789-793.

Brimer, L. and Molgaard, P. (1986). Biochem. Systematics and ECOI. 14, 97-103.

Brimer, L. and Rosling, H. (1993). Food Chem. Toxicol. in press.

Guignard, M.L. (1906). C.R. Hebd. Seances Acad. Sci. 142, 545553 .

Tunçel, G., Nout, M.J.R., Brimer, L. and Göktan, D. (1990). Int. J. Food Microbiol. 11, 337-344. 